\title{
Estimating stable isotope turnover rates of epidermal mucus and dorsal muscle for an omnivorous fish using a diet-switch experiment
}

\author{
Emily R. Winter • Emma T. Nolan • Georgina M. A. Busst $・$ J. Robert Britton $(\mathbb{D}$
}

Received: 21 April 2018/Revised: 24 October 2018/Accepted: 30 October 2018/Published online: 10 November 2018 (C) The Author(s) 2018

\begin{abstract}
Stable isotope (SI) analysis studies rely on knowledge of isotopic turnover rates and trophic-step discrimination factors. Epidermal mucus ('mucus') potentially provides an alternative SI 'tissue' to dorsal muscle that can be collected non-invasively and nondestructively. Here, a diet-switch experiment using the omnivorous fish Cyprinus carpio and plant- and fishbased formulated feeds compared SI data between mucus and muscle, including their isotopic discrimination factors and turnover rates (as functions of time $T$ and mass $G$, at isotopic half-life ( ${ }_{50}$ ) and equilibrium (95)). Mucus isotope data differed significantly and predictively from muscle data. The fastest $\delta^{13} \mathrm{C}$ turnover rate was for mucus in fish on the plant-based $\operatorname{diet}\left(T_{50}: 17\right.$ days, $T_{95}: 74$ days; $G_{50}: 1.08(\mathrm{BM}), G_{95}$ : $1.40(\mathrm{BM}))$. Muscle turnover rates were longer for the same fish $\left(T_{50}: 44\right.$ days, $T_{95}: 190$ days; $G_{50}$ : 1.13(BM), $G_{95}: 1.68(\mathrm{BM})$ ). Longer half-lives resulted
\end{abstract}

Handling editor: Michael Power

Electronic supplementary material The online version of this article (https://doi.org/10.1007/s10750-018-3816-4) contains supplementary material, which is available to authorised users.

E. R. Winter - E. T. Nolan - G. M. A. Busst .

J. R. Britton $(\square)$

Department of Life and Environmental Sciences, Faculty

of Science and Technology, Bournemouth University,

Poole BH12 5BB, UK

e-mail: rbritton@bournemouth.ac.uk in both tissues from the fish-based diet. $\delta^{13} \mathrm{C}$ discrimination factors varied by diet and tissue (plant-based: 3.11-3.28\%; fishmeal: 1.28-2.13\%o). Mucus SI data did not differ between live and frozen fish. These results suggest that mucus SI half-lives provide comparable data to muscle, and can be used as a non-destructive alternative tissue in fish-based SI studies.

Keywords Isotopic equilibrium · Isotopic half-life · Non-destructive sampling · Trophic-step discrimination factors

\section{Introduction}

Stable isotope turnover rates represent the change in mass and/or time required for consumer tissues to reflect their new diet, allowing the calculation of an isotopic half-life for the tissue and isotope of interest (Boecklen et al., 2011). Along with diet-tissue discrimination factors, turnover rates provide the basis of food web studies based on the isotopic composition of animal tissues (Vander Zanden et al., 2015). Tissues are considered at equilibrium with their diet after four to five half-lives (Hobson \& Clark, 1992; Busst \& Britton, 2018). As different tissues tend to have different turnover rates, they can potentially be used in combination to understand changes in consumer diet 
across different timescales (Phillips \& Eldridge, 2006; Maruyama et al., 2017).

Fishes are often utilised in aquatic isotope studies as they structure ecosystems and communities that matter to people, and can cause top-down effects (Kishi et al., 2005; Eby et al., 2006). In general, samples taken from fish for stable isotope analysis (SIA) are of white dorsal muscle ('muscle'). This is because it is considered the tissue that best represents fish diet isotopically (Busst et al., 2015), and provides a relatively long temporal integration of their dietary resources (Vander Zanden et al., 2015). Muscle samples are usually collected from euthanised fishes. This is potentially problematic where destructive sampling is either not desirable (e.g. in mark-recapture studies) or permitted (e.g. threatened or endangered species) (Vašek et al., 2017). Increasingly, the noninvasive and/or non-destructive collection of alternative tissues, such as fin and scales, is used (Busst et al., 2015; Busst \& Britton, 2016).

An issue with using fin and scale tissues in fishes is that their isotopic half-lives can be longer than those of dorsal muscle (Busst \& Britton, 2018). Thus, where rapid dietary changes need to be detected, their substitutive use might be unsuitable, or require application to mathematical models to account for the differences in turnover (Hertz et al., 2016). In general, blood, plasma and liver have shorter halflives than dorsal muscle (Thomas \& Crowther, 2015; Vander Zanden et al., 2015). As with dorsal muscle, however, these must be sampled either invasively or destructively. In addition, as half-life generally increases with body size, it is important to understand the contribution of growth and metabolism to the turnover rate (Vander Zanden et al., 2015).

For fish stable isotope analyses (SIA), an alternative tissue to dorsal muscle is epidermal mucus ('mucus'). To date, a limited number of stable isotope studies on fish mucus suggest it has a relatively fast turnover rate. For example, in rainbow trout Oncorhynchus mykiss (Walbaum, 1792), mucus half-lives of $\delta^{13} \mathrm{C}$ and $\delta^{15} \mathrm{~N}$ were 30 and 36 days, versus 136 and 94 days for muscle (Church et al., 2009). Studies on fishes including Silurus asotus (Linnaeus, 1758), Rhinogobius sp. and Pseudorasbora parva (Temminck \& Schlegel, 1846) have also suggested mucus has a faster turnover rate than muscle (Maruyama et al., 2015, 2017; Shigeta et al., 2017). Nevertheless, there are considerable knowledge gaps relating to the SIA of mucus. Importantly, this includes whether it should be collected from live or frozen fish, with collection from live fish obviously preferable, as it is then a nondestructive and non-lethal method. Also, knowledge gaps remain on its rate of turnover in relation to fish body mass, the relative contributions of growth and metabolism to turnover, diet-step discrimination factors, and how mucus SI values compare with those of dorsal muscle.

To overcome these knowledge gaps, the aim of this study was to use diet-switch experiments to complete the following objectives: (i) determine the $\delta^{13} \mathrm{C}$ and $\delta^{15} \mathrm{~N}$ turnover rates of dorsal muscle and mucus as functions of change in body mass and time, the contributions of metabolism and growth to these turnover rates, and the diet-tissue discrimination factors; (ii) test differences in isotopic data of mucus and dorsal muscle sampled from the same fish; and iii) quantify the difference in the stable isotope values of mucus collected from live versus frozen fish. Common carp Cyprinus carpio (Linnaeus, 1758) was used throughout the study as the model species. The rationale for their use included its omnivorous diet and high utilisation in many aquatic stable isotope studies, such as to assess their invasion impacts (e.g. Britton et al., 2007; Zambrano et al., 2010; Cucherousset et al., 2012). Indeed, they are a highly invasive, omnivorous fish at global scales (e.g. Ho et al., 2013). Carp are also frequently used in ecological studies completed in controlled conditions (Vilizzi et al., 2015). Thus, they provided an ecologically relevant model species that is highly suitable for keeping in aquaria for extended periods and also readily available from local hatcheries.

\section{Materials and methods}

Diet-switch experiment to determine stable isotope turnover rates and discrimination factors

The stable isotope half-lives and discrimination factors of the fish were determined using a diet-switch experiment that used two different food resources that differed in their protein content and source. The first food resource was crushed pelletised fishmeal ('FM'; $45 \%$ protein, $10 \%$ fat, $1.4 \%$ crude fibre and $5.8 \%$ ash) that was manufactured by Coppens and purchased from a local fish feed suppler. It had a mean $\delta^{13} \mathrm{C}$ value 
of $-25.73 \pm 0.08 \%$ and $\delta^{15} \mathrm{~N}$ of $6.23 \pm 0.12 \%$ $(n=3)$. The second diet was a plant-based, pelletised 'wheatgerm' pellet of $2 \mathrm{~mm}$ diameter ('WG'; $20 \%$ protein, $6 \%$ fat (as oil), $2.5 \%$ crude fibre and $2.5 \%$ ash) that was manufactured by TetraPond and purchased from a local aquarium shop. It had a mean $\delta^{13} \mathrm{C}$ value of $-25.63 \pm 0.07 \%$ and $\delta^{15} \mathrm{~N}$ of $3.81 \pm 0.05 \%$ $(n=3)$. The two food resources thus had very similar $\delta^{13} \mathrm{C}$ values that could have represented a confounding factor in the experiment. However, previous work demonstrated that due to the differing nutrient content of the two feeds (e.g. $45 \%$ fishmeal derived protein versus $20 \%$ plant derived protein), their discrimination factors with fish tissues differ significantly (e.g. approximately $2.0 \%$; Busst \& Britton, 2016). The fishmeal-based feed has the lower discrimination factors with fish tissues (Busst \& Britton, 2016). Consequently, as the fish are exposed to their new diet, their growth and metabolic responses should result in a considerable isotopic shift in their tissues due to these different diet-tissue discrimination factors.

This diet-switch experiment utilised 54 juvenile $C$. carpio of mean starting mass $( \pm 95 \%$ CI $)$ $8.00 \pm 0.51 \mathrm{~g}$ (range 3.33-13.06 g). Their fork lengths were between 58 and $69 \mathrm{~mm}$. They were sourced from a pond aquaculture site in Southern England. On their transfer to the aquaria facility, they were acclimated for 10 days before being tagged with $7 \mathrm{~mm}$ passive integrated transponder (PIT) tags for individual identification. The fish were then split into two groups $(n=27)$ and used in an experimental design incorporating two feeding periods and the two diets. The first feeding period lasted 160 days. This was to allow the fish time to reach isotopic equilibrium, as literature suggested this duration should cover approximately four isotopic half-lives (Hobson \& Clark, 1992; Thomas \& Crowther, 2015). During this first feeding period, the two groups of fish were fed either the FM or WG diet. For the 27 fish on each diet, the fish were held in groups of 9 in three tanks (45 1 volume) at $18^{\circ} \mathrm{C}$ on a $12: 12$-h light:dark cycle. Water quality was maintained in the tanks via a flow-through filtration system, with the three tanks per diet arranged in a column. Water was pumped from a base unit containing the filter system up to the top tank; it then flowed through each tank and was returned to the base unit for re-filtering. The two groups of fish were kept in separate columns with individual filter systems to avoid diet contamination. Environmental enrichment in the tanks was identical, comprising artificial plants and plastic pipes of $65 \mathrm{~mm}$ diameter and $120 \mathrm{~mm}$ length for refugia. Feeding of the two diets was at ad libitum.

At the end of this first feeding period, the fish were removed from their tanks, scanned for their PIT tag and re-weighed. Three fish were then randomly selected from each diet group of 27 fish, euthanised (anaesthetic overdose; MS-222) and frozen individually in plastic sample bags. The remaining fish were then returned to their tanks and their diet switched to the other formulated feed for a further 160 days (i.e. fish on the WG diet were switched to the FM diet and vice versa). During this second 160-day feeding period, three fish from each diet group were selected randomly from their tanks every 20 days. These fish were also scanned for their PIT tag, euthanised, reweighed and frozen individually.

At the end of the experiment, all the frozen fish were defrosted individually after a minimum time of being frozen of 14 days. A sample of mucus was taken from their defrosted surface using a sterile cover slip. The rationale for collecting mucus with a cover slip relates to work completed in previous studies, where mucus has been collected and treated using a variety of methods. Church et al. (2009) primarily used defrosted frozen fish, with washings of collected mucus using reverse osmosis water, with filtering on a polycarbonate filter to remove debris, before a final rinse and then drying. Maruyama et al. (2015) also utilised defrosted fish, with the mucus sample collected by wiping with a GF/F filter that was then dried. Through a comparison of methods, Maruyama et al. (2015) demonstrated less error than Church et al. (2009), and so washing was not applied in our study. Prior to our experiment, trials suggested that mucus collection with a sterilised cover slip and storing in a $1.5-\mathrm{ml}$ sample tube provided a sufficient quantity of mucus for SIA (approximately $1 \mathrm{mg}$ dried mucus), with any scales and debris identified and removed under the microscope before the mucus was transferred to a sterile tube and dried. This technique provided larger abundance of mucus for analysis than collection using GF/F filters. Thus, collection using cover slips was the method employed throughout the experiments here. A sample of white dorsal muscle was also taken from each fish and transferred to a separate $1.5-\mathrm{ml}$ tube. These samples were then dried at $60^{\circ} \mathrm{C}$ for $48 \mathrm{~h}$. 
Comparison of mucus samples from live versus frozen fish

A second experiment compared the isotopic values of mucus samples between live and frozen fish. It ran concurrently with the experiment outlined above. It involved the use of 9 fish held in separate flow-through systems at the beginning of the second feeding period. Of these fish, 5 were switched from the FM to WG diet at the end of the first feeding period and 4 were switched from the WG to the FM diet. They were fed their new diets for the same 160-day period as the fish in the first experiment. This was to ensure that the fish would have a wider range in their stable isotope data for subsequent statistical testing. At the end of the second 160-day feeding period, these fish were removed from their tanks, anaesthetised (MS-222), and a fresh sample of mucus immediately taken using a sterile cover slip. Each fish was then euthanised (anaesthetic overdose; MS-222) and frozen individually in plastic sample bags. These fish were defrosted after 14 days and another mucus sample taken. The mucus samples were then dried at $60^{\circ} \mathrm{C}$ for $48 \mathrm{~h}$. Concomitantly, samples of both formulated feeds were taken and dried at the same temperature and the same duration.

All procedures in the experiments were completed under UK Home Office licence 70/8083 after approval by the Animal Welfare and Ethical Review Body of Bournemouth University.

Stable isotope analysis

All samples were bulk analysed for $\delta^{13} \mathrm{C}$ and $\delta^{15} \mathrm{~N}(\%)$ at the Cornell University Stable Isotope Laboratory, New York, USA. After being ground to powder and weighed precisely to $\sim 1000 \mu \mathrm{g}$, in tin capsules, the samples were analysed on a Thermo Delta V isotope ratio mass spectrometer (Thermo Scientific, Waltham, MA, USA) interfaced to a NC2500 elemental analyser (CE Elantach Inc., Lakewood, NJ, USA). These were verified for accuracy against internationally known reference materials, whose values are determined by the International Atomic Energy Agency (IAEA; Vienna, Austria), and calibrated against the primary reference scales for $\delta^{13} \mathrm{C}$ and $\delta^{15} \mathrm{~N}$ values. The accuracy and precision of the sample runs were tested after every 10 samples using a standard animal sample (mink) to compensate for possible machine drift and as a quality control measure. Analytical precision of the $\delta^{13} \mathrm{C}$ and $\delta^{15} \mathrm{~N}$ sample runs was estimated at 0.15 and $0.42 \%$, respectively.

\section{Stable isotope turnover rates}

The changes in $\delta^{13} \mathrm{C}$ and $\delta^{15} \mathrm{~N}$ for muscle and mucus during the second feeding period were modelled as functions of body mass (growth models) and time (time models). These turnover rates were estimated using models based on Eqs. (1)-(9).

For turnover rates based on fish growth, the first model (Model A) was adapted from a time-based equation of Hobson and Clark (1992). It used the growth increment (to $0.1 \mathrm{~g}$ ) produced by the fish during the second feeding period to predict $\delta^{13} \mathrm{C}$ and $\delta^{15} \mathrm{~N}$ in an exponential approach (Busst \& Britton, 2018):

$\delta Y_{m}=\delta Y_{\mathrm{eq}}+\left(\delta Y_{i}-\delta Y_{\mathrm{eq}}\right) e^{c m}$,

where $\delta Y_{m}$ is the predicted $\delta^{13} \mathrm{C}$ or $\delta^{15} \mathrm{~N}$ isotopic ratio of a tissue given the fish growth increment $m, \delta Y_{\text {eq }}$ is the model-fitted $\delta^{13} \mathrm{C}$ or $\delta^{15} \mathrm{~N}$ isotopic ratio in equilibrium with the experimental diet, $\delta Y_{i}$ is the initial $\delta^{13} \mathrm{C}$ or $\delta^{15} \mathrm{~N}$ isotopic ratio prior to the diet switch, and $c$ is the model-fitted turnover constant. $\delta Y_{i}$ was estimated using the mean $\delta^{13} \mathrm{C}$ or $\delta^{15} \mathrm{~N}$ of the fish collected at the end of first feeding period (i.e. Day 0 of the second feeding period; $n=3$ ). The increase in mass $(\mathrm{g})$ required to attain a given percentage tissue turnover $\left(G_{\alpha}\right)$, specifically $50 \%$ (half-life, $\left.G_{50}\right)$ and 95\% (equilibrium; $G_{95}$ ), was calculated as (Tieszen et al., 1983):

$G_{\alpha}=\ln \left(1-\frac{\alpha}{100}\right) / c$.

A second growth-based model (Model B) used the relative increase in mass during the second feeding period to predict $\delta^{13} \mathrm{C}$ and $\delta^{15} \mathrm{~N}$ (Fry \& Arnold, 1982):

$\delta Y_{W_{R}}=\delta Y_{\text {eq }}+\left(\delta Y_{i}-\delta Y_{\text {eq }}\right) W_{R}^{c}$,

where $\delta Y_{W_{R}}$ is the predicted $\delta^{13} \mathrm{C}$ or $\delta^{15} \mathrm{~N}$ isotopic ratio of a fish tissue given its mass ratio $W_{R}$ (final mass/ initial mass), and $\delta Y_{\mathrm{eq}}, \delta Y_{i}$ and $c$ are as previously defined in Eq. (1). The amount of relative growth ( $\mathrm{X}-$ fold increase) needed to attain a given percentage tissue turnover $\left(G_{\alpha}\right)$ was calculated as (Buchheister \& Latour, 2010): 


$$
G_{\alpha}=\mathrm{e}^{\ln \left(1-\frac{\alpha}{100}\right) / c} .
$$

In Model $\mathrm{B}$, if $c=-1$, tissue turnover can be attributed solely to growth, whereas a value of $c<-1$ signifies the contribution of metabolism. The proportions of tissue turnover derived from growth $P_{g}$ and metabolism $P_{m}$ were calculated at the midpoint between the old and new diet values (Witting et al., 2004):

$P_{g}=\frac{2\left(G_{50}-1\right)}{G_{50}}$,

$P_{m}=\frac{2-G_{50}}{G_{50}}$.

Modelling the stable isotope turnover rates of muscle and mucus as an exponential function of time (as Day 0-160 in the second feeding period) used (Hesslein et al., 1993):

$\delta Y_{t}=\delta Y_{\mathrm{eq}}+\left(\delta Y_{i}-\delta Y_{\mathrm{eq}}\right) e^{-(k+m) t}$,

where $\delta Y_{t}$ is the predicted $\delta^{13} \mathrm{C}$ or $\delta^{15} \mathrm{~N}$ isotopic ratio of a fish tissue at time $t, \delta Y_{\text {eq }}$ and $\delta Y_{i}$ are as previously defined in (1), $m$ is the model-fitted metabolic turnover constant, and $k$ is the growth rate parameter, estimated using

$k=\ln \left(W_{R}\right) / t$.

In the first time-based model (Model C), $k$ was fixed for each experimental diet, while in the second timebased model (Model D), $k$ was variable and was estimated for each individual fish. The amount of time (days) required to achieve a given percentage tissue turnover $\left(T_{\alpha}\right)$ was calculated as (Tieszen et al., 1983):

$T_{\alpha}=-\ln \left(1-\frac{\alpha}{100}\right) /(k+m)$.

In Model $\mathrm{D}$, values of $T_{\alpha}$ were calculated for each individual fish and averaged across each experimental diet. Where $m=0$ in either of the time-based models, tissue turnover can be attributed solely to growth, whereas a value of $m>0$ indicates the contribution of metabolism. The proportions of tissue turnover derived from growth $P_{g}$ and metabolism $P_{m}$ were thus calculated as the ratio of each parameter to the sum of the two parameters $(k+m)$. Curve fitting and plotting was performed by non-linear regression in R 3.4.2 ( $\mathrm{R}$ Core Team, 2017), using the 'nls' function.
Stable isotope turnover model fitting and selection

The best-fitting growth- and time-based models for each isotope-tissue-diet combination were determined using the minimisation of Akaike's information criterion values, corrected for small sample sizes $\left(\mathrm{AIC}_{\mathrm{c}}\right)$. This was performed in R 3.4.2 (R Core Team, 2017) using the AICcmodavg package (Mazerolle, 2017). Models with the lowest $\mathrm{AIC}_{\mathrm{c}}$ values were deemed to have the most empirical support; however, models with $\Delta \mathrm{AIC}_{\mathrm{c}}$ (where this represents a measure of each model relative to the best model) values between 0 and 2 also had substantial support (Burnham \& Anderson, 2002).

Stable isotope discrimination factors

Trophic-step discrimination factors (TDF) were calculated for muscle and mucus per diet during the second feeding period. $\mathrm{TDF}_{\text {final }}$ represented the difference between the mean isotopic signature of the experimental diet and the mean $\delta^{13} \mathrm{C}$ or $\delta^{15} \mathrm{~N}$ of fish collected at the end of the experiment (Day 160), while $\mathrm{TDF}_{\text {asymp }}$ was estimated by subtracting the mean $\delta^{13} \mathrm{C}$ or $\delta^{15} \mathrm{~N}$ value of the experimental diet from the predicted equilibrium value $\left(\delta Y_{\text {eq }}\right)$ of the best-fitting model.

\section{Additional data analyses}

Differences in the mass increments of the fish between the two diets in the second feeding period (where the increment was determined as the final mass of the fish minus its mass at the start of the second feeding period) were tested in a generalised linear model. Increment was the dependent variable, diet was the independent variable, and covariates were mass at Day 0 (starting mass) of the second feeding period and the number of days to produce the increment in the second feeding period (time). Model outputs were the mean mass increments adjusted for the effects of covariates and the significance of their difference according to linearly independent pairwise comparisons with Bonferroni adjustment for multiple comparisons.

Differences in $\delta^{15} \mathrm{~N}$ and $\delta^{13} \mathrm{C}$ values between mucus samples collected from live and frozen fish, and the differences between mucus and dorsal muscle samples, were tested using linear regression. In 
addition to indicating the significance of the relationship, the regression coefficient $(b)$ was used to identify whether the isotopic values of each method and tissue were significantly different. This was indicated when the $95 \%$ confidence intervals of $b$ did not overlap 1.0. Where appropriate, the regression equation was provided to enable conversion of mucus data to muscle data.

Throughout the results, error around the mean is expressed as $95 \%$ confidence limits unless stated otherwise.

\section{Results}

Stable isotope data of the experimental fish between Day 0 and Day 160

At the end of the second feeding period, the mean C:N ratios of fish that consumed the FM diet were $3.61 \pm 0.09$ (range 3.31-4.11) for muscle and $3.80 \pm 0.05$ (3.40-4.00) for mucus. For fish consuming the WG diet, they were $3.72 \pm 0.14$ (3.29-4.58) for muscle and $3.85 \pm 0.08$ (3.51-4.50) for mucus.

In this second feeding period, the diet switches resulted in considerable changes in the $\delta^{13} \mathrm{C}$ of the fish in both mucus and muscle. For the fish with FM as the new diet, the mean $\delta^{13} \mathrm{C}$ of mucus on Day 0 was $-22.69 \pm 0.30 \%$ and on Day 160 was $-24.24 \pm 0.07 \%$ o (mean isotopic change: $1.55 \%$ ) (Fig. 1). For muscle of fish on the FM diet, the mean $\delta^{13} \mathrm{C}$ on Day 0 was $-22.03 \pm 0.43 \%$ and on Day 160 was $-23.77 \pm 0.43 \%$ (mean isotopic change: $1.74 \%$ ) (Fig. 1). On the WG diet, the mean $\delta^{13} \mathrm{C}$ of mucus on Day 0 was $-23.89 \pm 0.22 \%$ and on Day 160 was $-22.52 \pm 0.12 \%$ o (mean isotopic change: $1.37 \%$ ) (Fig. 1). For muscle of fish on the WG diet, the mean $\delta^{13} \mathrm{C}$ on Day 0 was $-23.57 \pm 0.31 \%$ and on Day 160 was $-22.47 \pm 0.34 \%$ (mean isotopic change: $1.10 \%$ ) (Fig. 1).

For $\delta^{15} \mathrm{~N}$, for the fish with FM as the new diet, the mean $\delta^{15} \mathrm{~N}$ of mucus on Day 0 was $8.56 \pm 0.09 \%$ and on Day 160 was $8.22 \pm 0.20 \%$ (mean isotopic change: $0.34 \%$ ) (Fig. 1). For muscle of fish on the FM diet, the mean $\delta^{15} \mathrm{~N}$ on Day 0 was $9.51 \pm 0.33 \%$ o and on Day 160 was $8.43 \pm 0.2 \%$ (mean isotopic change: $1.08 \%$ ) (Fig. 1). The minor isotopic change in mucus on the FM diet in the second feeding period meant the turnover rates for $\delta^{15} \mathrm{~N}$ on the FM data were
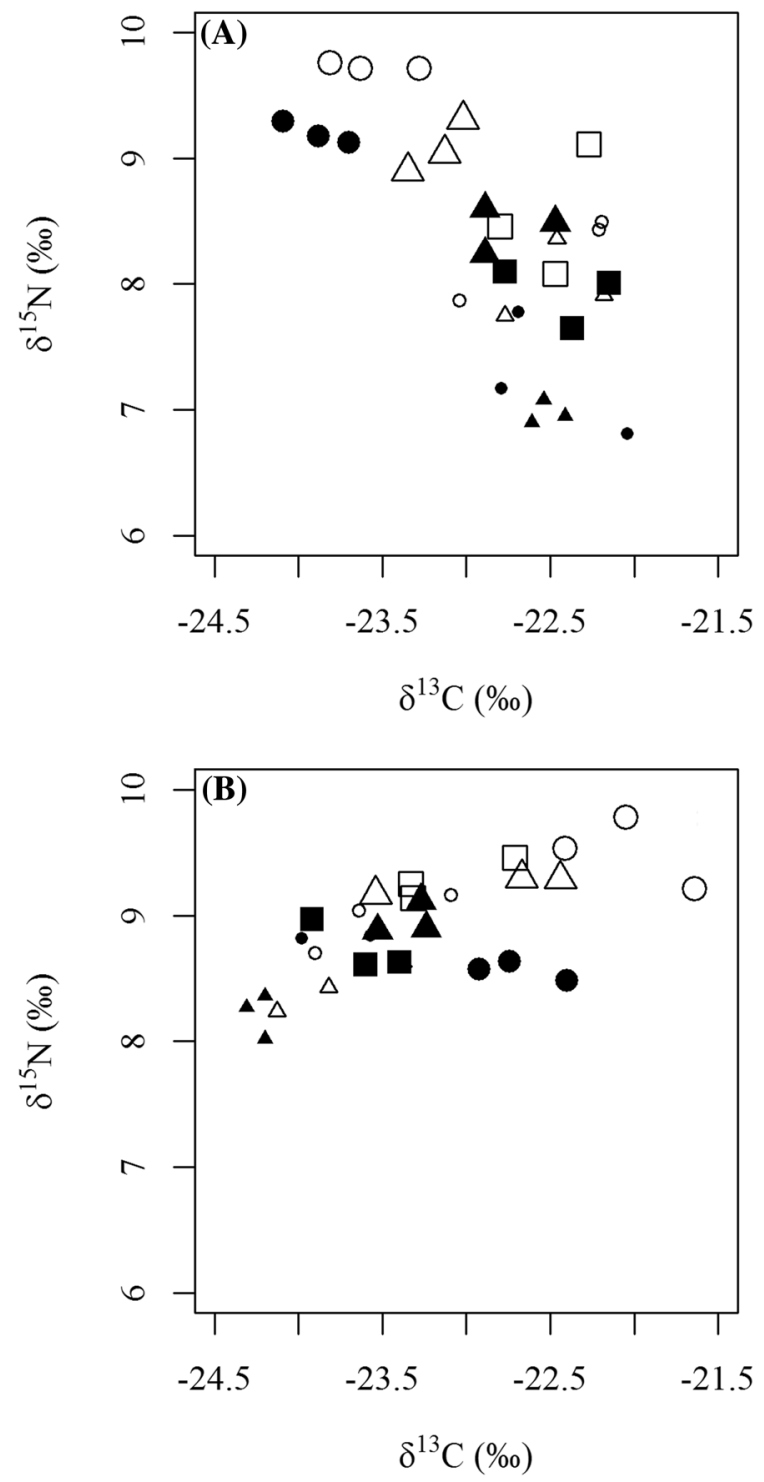

Fig. 1 Stable isotope biplots over the course of the second 160-day feeding period following the diet switch for Cyprinus carpio to the (A) WG diet, and (B) FM diet, and for dorsal muscle (clear symbols) and mucus (filled symbols). Large circles: Day 0; large triangle: Day 40; large square: Day 80, small circle: Day 120; small triangle: Day 160

not modelled. On the WG diet, the mean $\delta^{15} \mathrm{~N}$ of mucus on Day 0 was $9.19 \pm 0.20 \%$ and on Day 160 was $6.97 \pm 1.0 \%$ o (mean isotopic change: $2.22 \%$ ) (Fig. 1). For muscle of fish on the WG diet, the mean $\delta^{15} \mathrm{~N}$ on Day 0 was $9.72 \pm 0.03 \%$ and on Day 160 was $8.01 \pm 0.36 \%$ (mean isotopic change: $1.71 \%$ ) (Fig. 1). These isotopic changes for $\delta^{15} \mathrm{~N}$ on the WG 


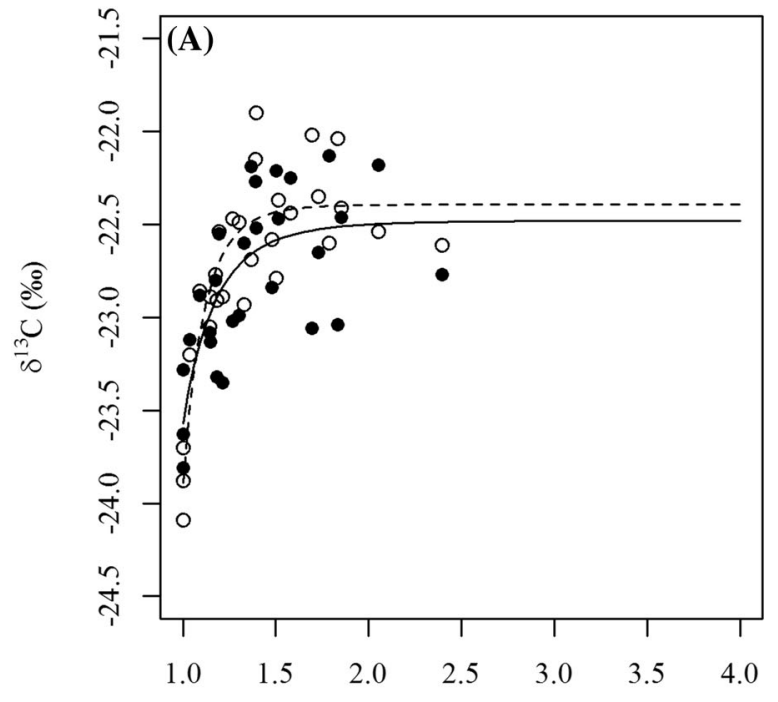

Relative Increase in Mass

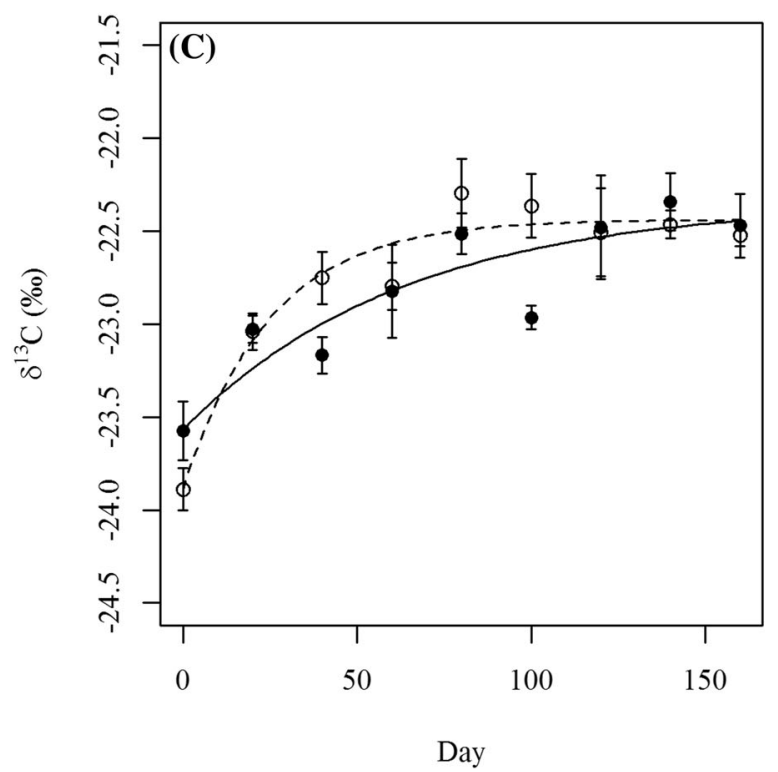

Fig. 2 Relationships of changes in $\delta^{13} \mathrm{C}$ as functions of increased fish mass and time in the second feeding period of the main experiment. Changes to Cyprinus carpio $\delta^{13} \mathrm{C}$ as a function of relative increase in mass $(\mathbf{A}, \mathbf{B})$ and time (as mean $\left.\pm \mathrm{CI} \delta^{13} \mathrm{C}\right)(\mathbf{C}, \mathbf{D})$, and according to muscle (filled circles) and epidermal mucus (open circles), and the WG diet

meant that these data were used in the turnover models.
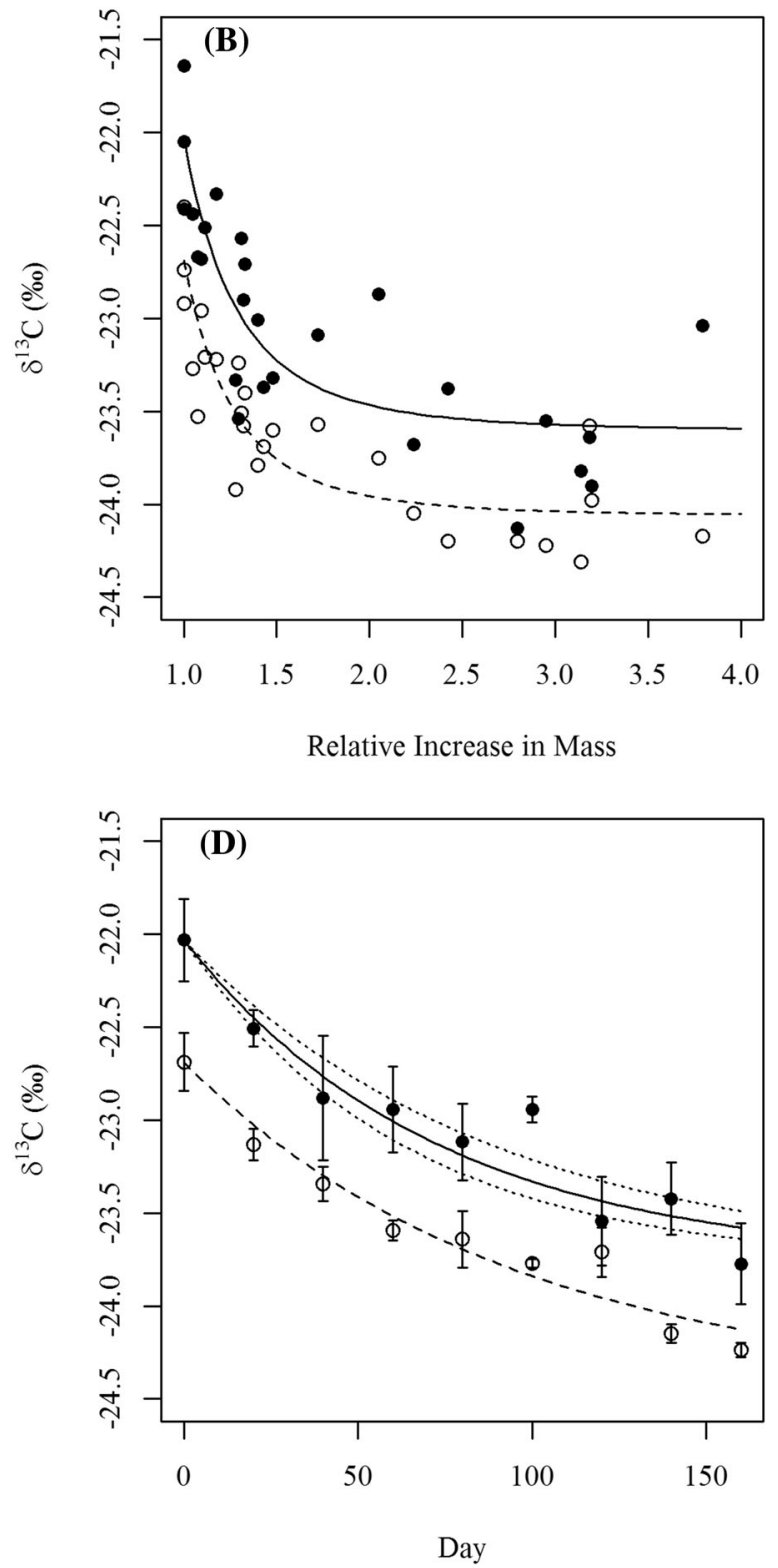

$(\mathbf{A}, \mathbf{C})$ and FM diet $(\mathbf{B}, \mathbf{D}) . N=27$ per tissue and diet per plot. The diets WG and FM refer to the second 160-day feeding period. Curves are displayed according to the best-fitting model equations for muscle (solid line) and mucus (dashed line). Dotted lines in panel (D) represent 95\% CI around the mean of $k$

Fish growth increments in the experimental period

Mean fish mass at the start of the experiment was $8.0 \pm 0.5 \mathrm{~g}$ and increased to $14.7 \pm 1.2 \mathrm{~g}$ at the end of the first feeding period. At the end of the second feeding period, mean fish mass had increased further 

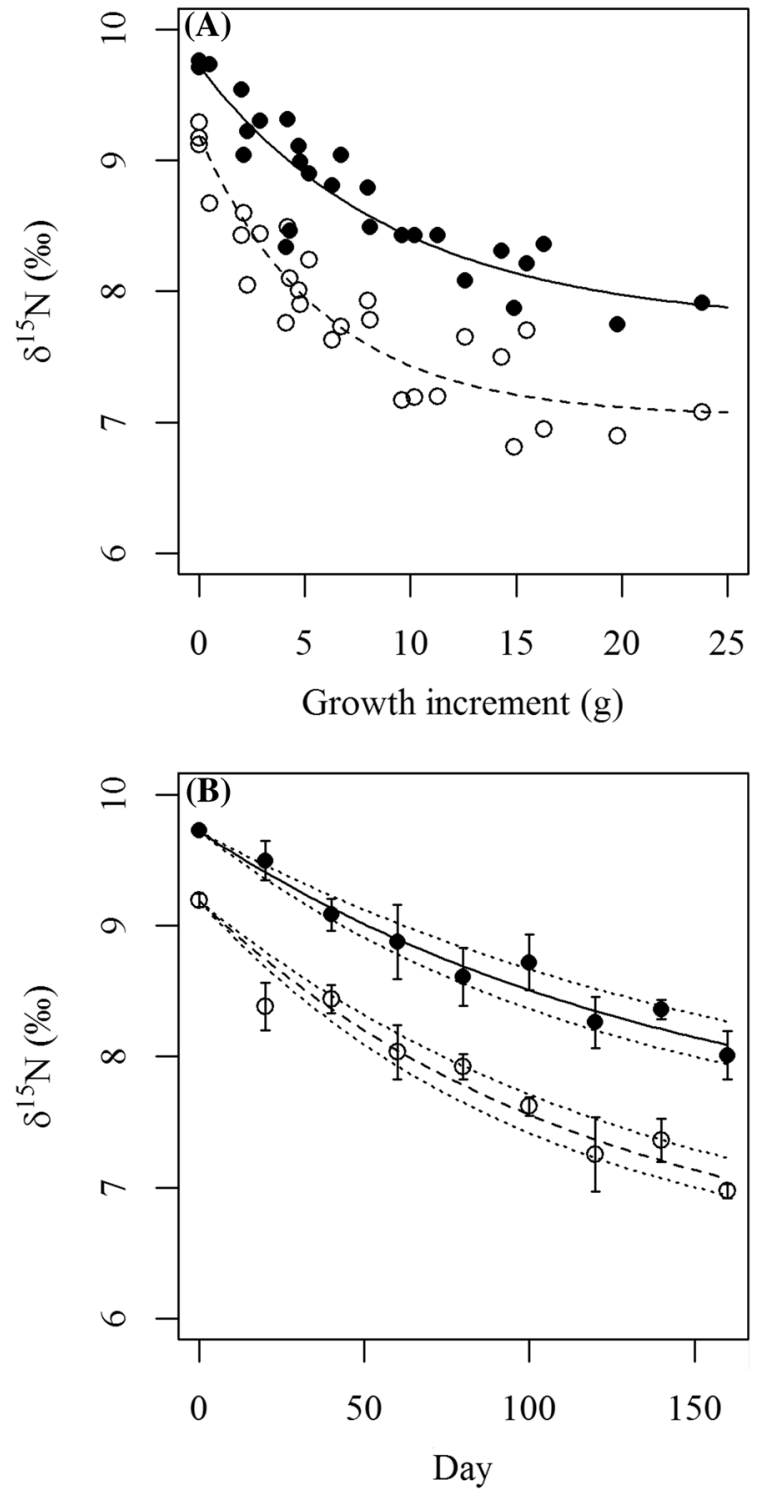

Fig. 3 Relationships of changes in $\delta^{15} \mathrm{~N}$ as functions of increased fish mass and time in the second feeding period of the main experiment. Changes to Cyprinus carpio $\delta^{15} \mathrm{~N}$ as a function of growth increment (A) and time (as mean $\left.\pm \mathrm{CI} \delta^{15} \mathrm{~N}\right)$ (B), and according to muscle (filled circles) and epidermal mucus (open circles) on the WG diet. $N=27$ per tissue per plot. The diet WG refers to the second 160-day feeding period. Curves are displayed according to the best-fitting model equations for muscle (solid line) and mucus (dashed line). Dotted lines in panel (B) represent 95\% CI around the mean of $k$

to $22.1 \pm 2.1 \mathrm{~g}$, with a mean increment in this second period of $7.4 \pm 1.7 \mathrm{~g}$. The GLM testing differences in mass increments between the two diets in the second feeding period was significant (Wald $\chi^{2}=18.90$,
$P<0.01)$, with the covariates of starting mass and time being significant in the model $(P<0.01)$. Mean mass increment on the FM diet was $10.0 \pm 0.1 \mathrm{~g}$ and on the WG diet was $6.7 \pm 0.1 \mathrm{~g}$. The differences in mean mass were then reflected in the diet-specific growth rates $(k)$ of $0.0064 \pm 0.0003$ for FM fish, and $0.0041 \pm 0.0002$ for $\mathrm{WG}$ fish. During the second feeding period, values of $\delta^{13} \mathrm{C}$ and $\delta^{15} \mathrm{~N}$ for muscle and mucus tissue increased or decreased depending on their initial and new diet (Figs. 1, 2, 3).

Stable isotope half-life models and trophic discrimination factors

For growth-based turnover models predicting $\delta^{13} \mathrm{C}$, the best-fitting model was always Model B (Tables 1, $2 \mathrm{a}, \mathrm{S} 1)$. For time-based models predicting $\delta^{13} \mathrm{C}$, the best-fitting model for muscle varied by diet, with Model $\mathrm{C}$ being the best fit for WG and Model D for FM diet (Tables 1, 2b, S1). By contrast, Model C was always the best fit for mucus (Tables 1, 2b). Comparison of turnover rates between the tissues revealed that in fish feeding on the WG diet in the second feeding period, mucus has the more rapid turnover (Table 2). However, this was not apparent for fish on the FM diet, where turnover rates were more similar between the two tissues (Table 2).

When predicting $\delta^{15} \mathrm{~N}$ using growth-based models, the best-fitting model was consistently Model A (Tables 1, 3a, S2), while for time-based models the best-fitting model was consistently Model D (Tables $1,3 \mathrm{~b}, \mathrm{~S} 2$ ). As with $\delta^{13} \mathrm{C}$ on the $\mathrm{WG}$ diet, mucus $\delta^{15} \mathrm{~N}$ showed a faster rate of turnover than muscle; however, estimates of half-life $\left(G_{0.5} ; T_{0.5}\right)$ and near complete turnover $\left(G_{0.95} ; T_{0.95}\right)$ were always greater for $\delta^{15} \mathrm{~N}$ than for $\delta^{13} \mathrm{C}$, including those from alternative models with $\Delta \mathrm{AIC}_{\mathrm{c}} \leq 2$ (Tables $2,3, \mathrm{~S} 1$, S2).

For both tissues and diets, growth and metabolism both contributed to the $\delta^{13} \mathrm{C}$ and $\delta^{15} \mathrm{~N}$ turnover rates, as indicated by values of $c<-1$ in Model B and $m>0$ in Models C and D. For the WG diet, metabolism played a greater role in the turnover of mucus than of muscle for both $\delta^{13} \mathrm{C}(74-77 \%)$ and $\delta^{15} \mathrm{~N}(53 \%)$. Conversely, for the FM diet, metabolism played an equal or lesser role in the turnover of mucus $\delta^{13} \mathrm{C}(39-66 \%)$ than of muscle $\delta^{13} \mathrm{C}(60-64 \%)$ (Tables 2, 3). 
Table 1 Comparisons of $\Delta \mathrm{AIC}_{\mathrm{c}}$ among growth- and time-based models of $\delta^{13} \mathrm{C}$ and $\delta^{15} \mathrm{~N}$ turnover

\begin{tabular}{|c|c|c|c|c|c|c|c|c|c|c|}
\hline \multirow[t]{3}{*}{ Method } & \multirow[t]{3}{*}{ Diet } & \multirow[t]{3}{*}{ Tissue } & \multicolumn{8}{|l|}{$\Delta \mathrm{AIC}_{\mathrm{c}}$} \\
\hline & & & \multicolumn{4}{|l|}{$\delta^{13} \mathrm{C}$} & \multicolumn{4}{|l|}{$\delta^{15} \mathrm{~N}$} \\
\hline & & & Model A & Model B & Model C & Model D & Model A & Model B & Model C & Model D \\
\hline \multirow[t]{4}{*}{ Growth-based } & WG & Muscle & 2.47 & 0.00 & - & - & 0.00 & 12.40 & - & - \\
\hline & & Mucus & 3.64 & 0.00 & - & - & 0.00 & 0.31 & - & - \\
\hline & FM & Muscle & 0.85 & 0.00 & - & - & - & - & - & - \\
\hline & & Mucus & 1.49 & 0.00 & - & - & - & - & - & - \\
\hline \multirow[t]{4}{*}{ Time-based } & WG & Muscle & - & - & 0.00 & 0.52 & - & - & 1.42 & 0.00 \\
\hline & & Mucus & - & - & 0.00 & 1.16 & - & - & 3.59 & 0.00 \\
\hline & FM & Muscle & - & - & 3.88 & 0.00 & - & - & - & - \\
\hline & & Mucus & - & - & 0.00 & 3.49 & - & - & - & - \\
\hline
\end{tabular}

Note that 'Diet' refers only to the second 160-day feeding period only

The $\Delta^{13} \mathrm{C}$ for the WG diet ranged from 3.11 to $3.24 \%$ or mucus, and from 3.15 to $3.28 \%$ for muscle. For the FM diet, $\Delta^{13} \mathrm{C}$ was $1.28-1.67 \%$ for mucus and $1.96-2.13 \%$ for muscle, indicating a clear difference between the two food sources despite their similar $\delta^{13} \mathrm{C}$ values (Table 2). The $\Delta^{15} \mathrm{~N}$ for the WG diet showed greater variation and ranged from 2.54 to $3.24 \%$ for mucus and from 3.45 to $4.20 \%$ for muscle (Table 3). The $\mathrm{TDF}_{\text {final }}$ and $\mathrm{TDF}_{\text {asymp }}$ values were similar within each isotope-tissue-diet combination, suggesting that $\delta^{13} \mathrm{C}$ and $\delta^{15} \mathrm{~N}$ had reached, or at least approached, isotopic equilibrium with the new diets (Figs. 2, 3).

Comparison of stable isotope values between tissues and live versus frozen fish

The relationship of $\delta^{13} \mathrm{C}$ for mucus versus muscle was significant $\left(R^{2}=0.45 ; F_{1,52}=42.2, P<0.01\right)$, with the $95 \%$ confidence intervals of $b$ significantly different to 1.0 (0.38-0.72) (Fig. 4). The relationship of $\delta^{15} \mathrm{~N}$ for mucus and muscle was also significant $\left(R^{2}=0.64 ; F_{1,52}=90.2, P<0.01\right)$, with the $95 \%$ confidence intervals of $b$ significantly different to 1.0 (0.50-0.77) (Fig. 4).

The relationship between mucus taken from live and frozen fish was positive and significant for $\delta^{13} \mathrm{C}$ $\left(R^{2}=0.99 ; \quad F_{1,7}=2401.8, \quad P<0.01\right) \quad$ and $\quad \delta^{15} \mathrm{~N}$ $\left(R^{2}=0.99 ; F_{1,7}=643.3, P<0.01\right)$ (Fig. 4). For both isotopes, the $95 \%$ confidence intervals of $b$ were not significantly different to $1.0\left(\delta^{13} \mathrm{C}: 0.97-1.07 ; \delta^{15} \mathrm{~N}\right.$ : 0.91-1.10).

\section{Discussion}

The results revealed that epidermal mucus collected from live fish provides a non-invasive and nondestructive tissue for use in stable isotope analyses that can replace the use of dorsal muscle. However, the results also revealed that there can be differences in the turnover rates of mucus versus muscle, although this was dependent on the diet, and this would need consideration when mucus is used within stable isotope field studies. For $\delta^{13} \mathrm{C}$, mucus turnover rates were more rapid than muscle on the WG diet, but were similar on the FM diet. For $\delta^{15} \mathrm{~N}$, mucus turnover rates were always lower than muscle. These generally lower turnover rates of mucus compared with muscle were consistent with findings from the small number of other studies that have compared the turnover rates of mucus versus muscle for other fish species (e.g. Maruyama et al., 2015, 2017; Shigeta et al., 2017). In our experiment, the turnover rates of $\delta^{15} \mathrm{~N}$ were also always greater than the rates measured for $\delta^{13} \mathrm{C}$, irrespective of diet and tissue. This finding was consistent for those of $O$. mykiss, where for $\delta^{13} \mathrm{C}$, turnover rates were 30 and 36 days for mucus and muscle, respectively, but were 136 and 94 days, respectively, for $\delta^{15} \mathrm{~N}$ (Church et al., 2009). 


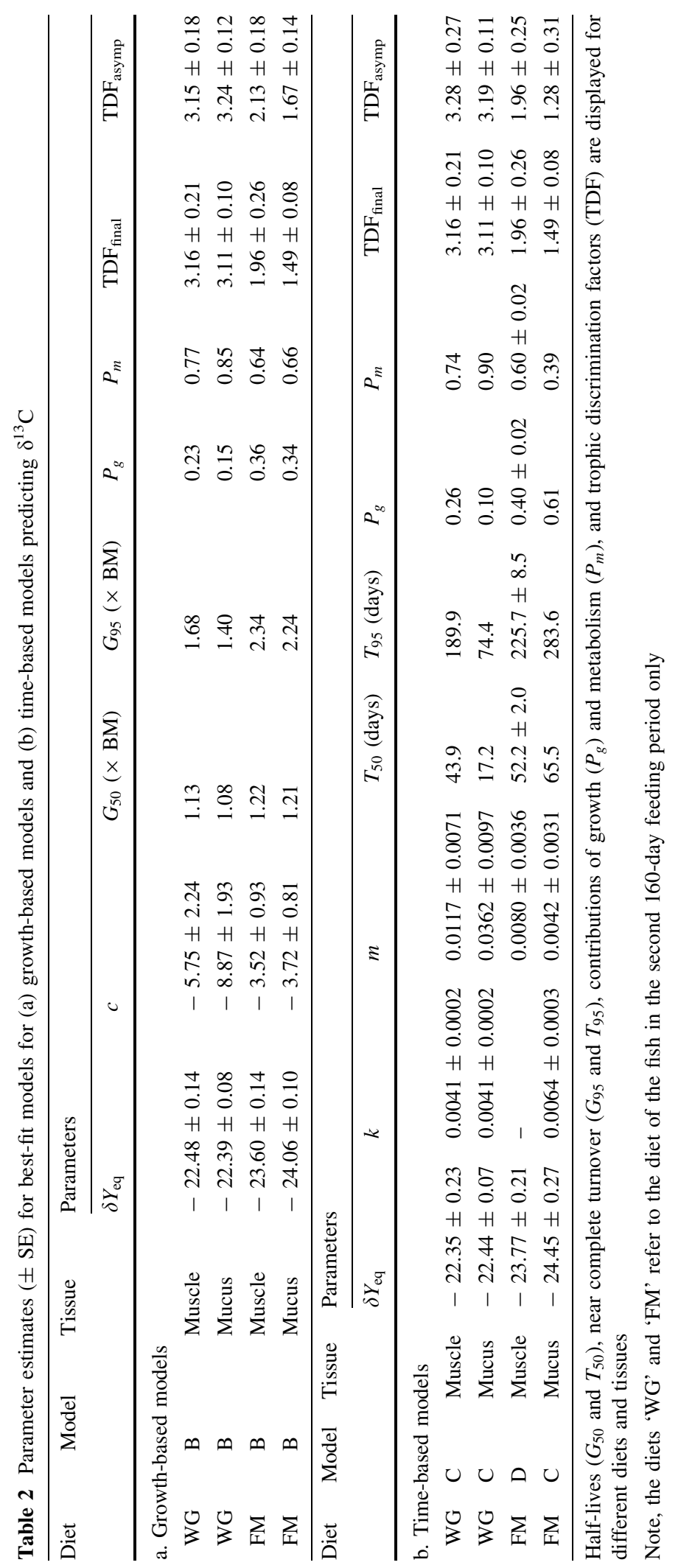


Table 3 Parameter estimates ( \pm SE) for best-fit models for (a) growth-based models and (b) time-based models predicting $\delta^{15} \mathrm{~N}$

\begin{tabular}{|c|c|c|c|c|c|c|c|c|c|c|c|c|}
\hline \multirow[t]{2}{*}{ Diet } & \multirow[t]{2}{*}{ Model } & \multirow{2}{*}{\multicolumn{2}{|c|}{ Tissue }} & \multicolumn{9}{|c|}{ Parameters } \\
\hline & & & & \multicolumn{2}{|l|}{$\delta Y_{\mathrm{eq}}$} & \multicolumn{2}{|l|}{$c$} & $G_{50}(\mathrm{~g})$ & \multicolumn{2}{|l|}{$G_{95}(\mathrm{~g})$} & $\mathrm{TDF}_{\text {final }}$ & $\mathrm{TDF}_{\text {asymp }}$ \\
\hline \multicolumn{13}{|c|}{ a. Growth-based models } \\
\hline WG & A & \multicolumn{2}{|c|}{ Muscle } & \multicolumn{2}{|c|}{$7.74 \pm 0.24$} & \multicolumn{2}{|c|}{$-0.11 \pm 0.03$} & 6.44 & 27.84 & \multicolumn{2}{|r|}{$4.20 \pm 0.21$} & $3.93 \pm 0.28$ \\
\hline WG & A & \multicolumn{2}{|c|}{ Mucus } & \multicolumn{2}{|c|}{$7.05 \pm 0.15$} & \multicolumn{2}{|c|}{$-0.17 \pm 0.03$} & 4.05 & 17.49 & & $3.17 \pm 0.08$ & $3.24 \pm 0.18$ \\
\hline \multirow[t]{2}{*}{ Diet } & \multirow[t]{2}{*}{ Model } & \multirow[t]{2}{*}{ Tissue } & \multicolumn{10}{|c|}{ Parameters } \\
\hline & & & $\delta Y_{\mathrm{eq}}$ & & $m$ & & $T_{50}$ (days) & $T_{95}$ (days) & $P_{g}$ & $P_{m}$ & $\mathrm{TDF}_{\text {final }}$ & $\mathrm{TDF}_{\text {asymp }}$ \\
\hline \multicolumn{13}{|c|}{ Time-based models } \\
\hline WG & $\mathrm{D}$ & Muscle & 7.26 & $=0.51$ & 0.0028 & 0.002 & 102.0 & 440.9 & 0.59 & 0.41 & $4.20 \pm 0.21$ & $3.45 \pm 0.54$ \\
\hline WG & $\mathrm{D}$ & Mucus & 6.35 & $=0.37$ & 0.0045 & 0.002 & 81.1 & 350.5 & 0.47 & 0.53 & $3.17 \pm 0.08$ & $2.54 \pm 0.40$ \\
\hline
\end{tabular}

Half-lives $\left(G_{50}\right.$ and $\left.T_{50}\right)$, near complete turnover $\left(G_{95}\right.$ and $\left.T_{95}\right)$, contributions of growth $\left(P_{g}\right)$ and metabolism $\left(P_{m}\right)$, and trophic discrimination factors (TDF) are displayed for different diets and tissues

Note, the diets 'WG' and 'FM' refer to the diet of the fish in the second 160-day feeding period only

The stable isotope turnover rates were modelled here as functions of both time and mass. The use of mass in the models was important, as several stable isotope studies have highlighted the positive relationship between stable isotope turnover rates and body mass (Carleton \& Martínez del Rio, 2005; Vander Zanden et al., 2015). Indeed, allometric studies suggest isotopic half-lives are consistently related to increased mass (e.g. Weidel et al., 2011). Moreover, in many fishes, the role of body size and/or change in mass in the isotopic turnover rates of different tissues is arguably more important than time. This is because fish growth rates are indeterminate and highly variable, being influenced by a range of abiotic (e.g. water temperature) and biotic (e.g. food availability) factors (Beardsley \& Britton, 2012). Here, the time-based models predicted that at $18^{\circ} \mathrm{C}$, dorsal muscle $\delta^{13} \mathrm{C}$ needed at least 190 days to reach isotopic equilibrium (as 95\% isotopic turnover), while $\delta^{15} \mathrm{~N}$ required at least 440 days (Tables 2, 3). Even for $\delta^{13} \mathrm{C}$, these durations would, in many temperate regions, cover more than one fish growth season (Britton, 2007). The growth-based models predicted that dorsal muscle $\delta^{13} \mathrm{C}$ reached isotopic equilibrium after a minimum of a 1.68-fold increase in body mass $(\times \mathrm{BM})$. As the growth-based models estimate turnover as a rate of change according to mass, they are more likely to be appropriate for applying to juvenile wild fishes, whose growth rates tend to be relatively fast (even in slow growing fishes) (Britton, 2007). This means these juvenile fish undergo rapid and substantial changes in body mass (Froese, 2006). Growthbased models might, however, be less applicable for use in large and/or older fishes, as a result of their relatively slow growth rates (Hesslein et al., 1993; Herzka \& Holt, 2000; Perga \& Gerdeaux, 2005). In these fishes, experimental studies have suggested that the contribution of growth to isotopic replacement is relatively low with, for example, metabolic replacement contributing up to $80 \%$ of isotopic change in dorsal muscle (Suzuki et al., 2005; Logan et al., 2006; Tarboush et al., 2006). In the present study, metabolism always contributed more to the tissues whose rates of isotopic turnover were fastest, in line with previous findings (Heady \& Moore, 2013), yet even for muscle, metabolism contributed to the majority of $\delta^{13} \mathrm{C}$ turnover (60-77\%). This may be explained by limited growth due to husbandry in aquaria conditions, and perhaps suggests the utility of these results in also predicting turnover for older and slower growing fishes.

In the experiment, there was a potential confound over the $\delta^{13} \mathrm{C}$ values of the two dietary items, given they were very similar. This raised concern that there would be negligible changes in the stable isotope data of the fish during the second feeding period. However, during the second feeding period, the shift in the $\delta^{13} \mathrm{C}$ values of the fish varied between 1.10 and $1.74 \%$. For $\delta^{15} \mathrm{~N}$, the difference in the second feeding period was $2.22 \%$ on the WG diet, but only $0.34 \%$ on the FM 

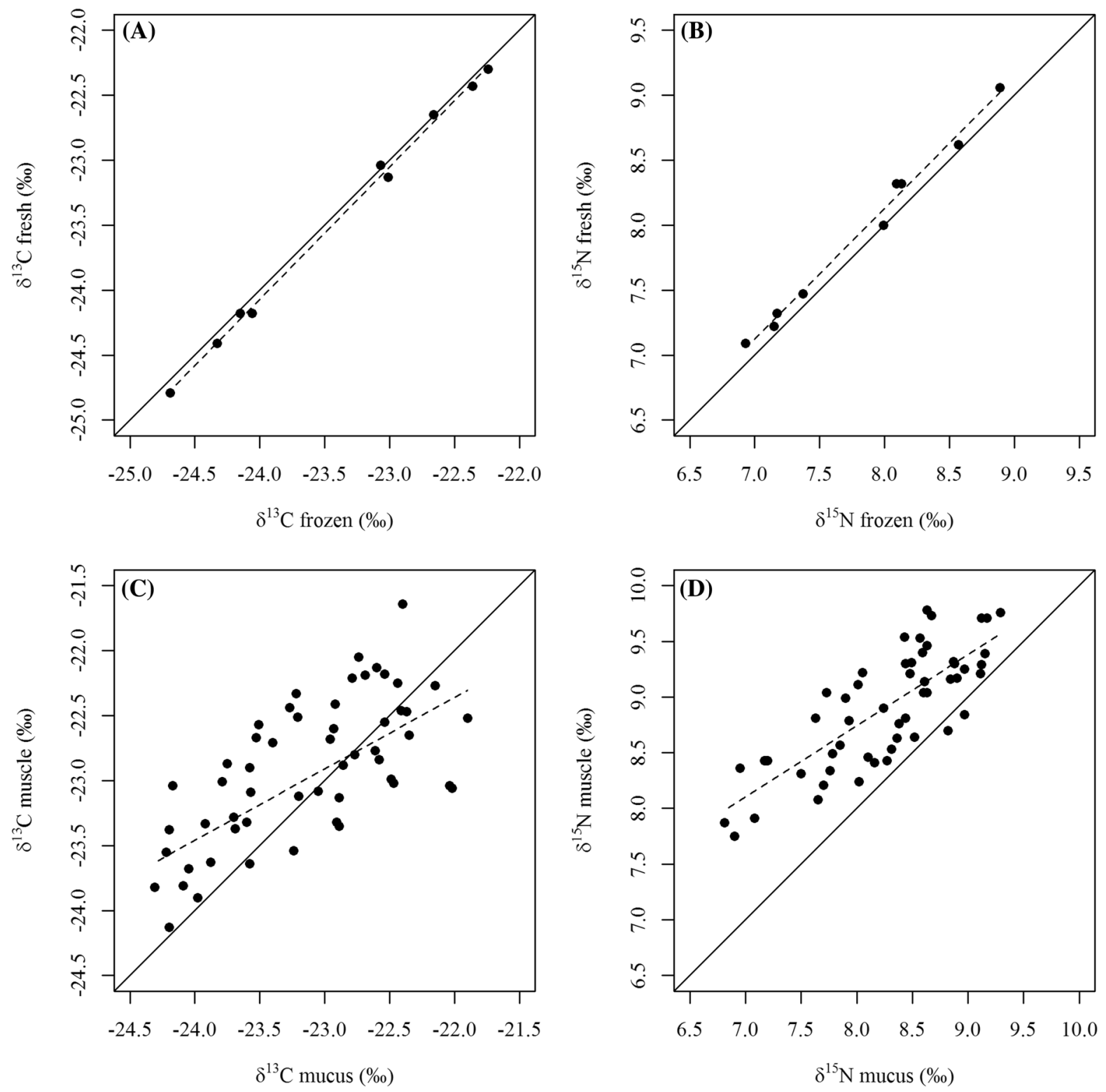

Fig. 4 Relationships of stable isotope data from frozen versus live fish, and mucus versus muscle. A, B Comparison of $\delta^{13} \mathrm{C}$ (A) and $\delta^{15} \mathrm{~N}$ (B) of frozen versus live mucus samples. $\mathbf{C}$, D Comparison of $\delta^{13} \mathrm{C}(\mathbf{C})$ and $\delta^{15} \mathrm{~N}$ (D) of epidermal mucus versus dorsal muscle. Straight lines denote the 1:1 line, and dashed lines represent the significant relationship of the

diet. Consequently, the $\delta^{13} \mathrm{C}$ turnover rates were modelled for both diets, but for $\delta^{15} \mathrm{~N}$, they were modelled only for the WG diet. For the modelled $\delta^{13} \mathrm{C}$ data, the differences in the stable isotope data across the second feeding period represented the response of the fish to the different tissue-diet discrimination

variables according to linear regression $(P<0.01) . N=9$ on plots $\mathrm{A}$ and $\mathrm{B} . N=54$ on plots $\mathrm{C}$ and $\mathrm{D}$. The regression equation for converting $\delta^{13} \mathrm{C}$ of mucus to muscle is 0.55 (mucus)-10.26; the regression equation for converting $\delta^{15} \mathrm{~N}$ of mucus to muscle is 0.64 (mucus) +3.62

factors of the diets that related to their different protein sources and content. As the FM and WG diets provided contrasting sources of dietary protein, the differences in their discrimination factors were most likely related to the protein quality hypothesis. This hypothesis predicts isotopic discrimination between 
consumers and their prey increases as the protein quality decreases (Roth \& Hobson, 2000). Given carnivores usually assimilate higher quality protein than herbivores, the result is discrimination factors decreasing as trophic level increases (Roth \& Hobson, 2000; Busst \& Britton, 2016). The fishmeal diet had the highest protein content ( $45 \%$ marine fish meal) and had the lowest discrimination factors for $\delta^{13} \mathrm{C}$ in both muscle $(1.96 \pm 0.26)$ and mucus $(1.49 \pm 0.08)$. The WG diet, with a protein content of $20 \%$ that was derived from plant material, then had considerably higher discrimination factors $(3.16 \pm 0.21$ for muscle; $3.11 \pm 0.10 \%$ for mucus).

In summary, the results suggested that mucus collected from live fish can provide a reliable alternative to dorsal muscle in aquatic stable isotope studies that can be sampled non-destructively and noninvasively. The increased application of epidermal mucus is thus recommended to aquatic isotope studies where either destructive sampling is not permitted, or the study design needs to incorporate a tissue that can have a relatively fast isotopic turnover rate.

Acknowledgements We gratefully acknowledge the support for ERW of the EU LIFE + Nature and Biodiversity Programme: LIFE14NAT/UK/000054.

Open Access This article is distributed under the terms of the Creative Commons Attribution 4.0 International License (http:// creativecommons.org/licenses/by/4.0/), which permits unrestricted use, distribution, and reproduction in any medium, provided you give appropriate credit to the original author(s) and the source, provide a link to the Creative Commons license, and indicate if changes were made.

\section{References}

Beardsley, H. \& J. R. Britton, 2012. Contribution of temperature and nutrient loading to growth rate variation of three cyprinid fishes in a lowland river. Aquatic Ecology 46: 143-152.

Boecklen, W. J., C. T. Yarnes, B. A. Cook \& A. C. James, 2011. On the Use of Stable Isotopes in Trophic Ecology. In Futuyma, D. J., H. B. Shaffer \& D. Simberloff (eds), Annual Review of Ecology, Evolution, and Systematics, Vol. 42. Palo Alto, Annual Reviews: 411-440.

Britton, J. R., 2007. Reference data for evaluating the growth of common riverine fishes in the UK. Journal of Applied Ichthyology 23: 555-560.

Britton, J. R., R. R. Boar, J. Grey, J. Foster, J. Lugonzo \& D. M. Harper, 2007. From introduction to fishery dominance: the initial impacts of the invasive carp Cyprinus carpio in
Lake Naivasha, Kenya, 1999 to 2006. Journal of Fish Biology 71: 239-257.

Buchheister, A. \& R. J. Latour, 2010. Turnover and fractionation of carbon and nitrogen stable isotopes in tissues of a migratory coastal predator, summer flounder (Paralichthys dentatus). Canadian Journal of Fisheries and Aquatic Sciences 67: 445-461.

Burnham, K. P. \& D. R. Anderson, 2002. Model selection and multi-model inference : a practical information-theoretic approach, 2nd ed. Springer, New York, London.

Busst, G. M. A. \& J. R. Britton, 2016. High variability in stable isotope diet-tissue discrimination factors of two omnivorous freshwater fishes in controlled ex situ conditions. Journal of Experimental Biology 219: 1060-1068.

Busst, G. M. A. \& J. R. Britton, 2018. Tissue-specific turnover rates of the nitrogen stable isotope as functions of time and growth in a cyprinid fish. Hydrobiologia 805: 49-60.

Busst, G. M. A., T. Basic \& J. R. Britton, 2015. Stable isotope signatures and trophic-step fractionation factors of fish tissues collected as non-lethal surrogates of dorsal muscle. Rapid Communications in Mass Spectrometry 29: 1535-1544.

Carleton, S. A. \& C. Martínez del Rio, 2005. The effect of coldinduced increased metabolic rate on the rate of C-13 and $\mathrm{N}-15$ incorporation in house sparrows (Passer domesticus). Oecologia 144: 226-232.

Church, M. R., J. L. Ebersole, K. M. Rensmeyer, R. B. Couture, F. T. Barrows \& D. L. G. Noakes, 2009. Mucus: a new tissue fraction for rapid determination of fish diet switching using stable isotope analysis. Canadian Journal of Fisheries and Aquatic Sciences 66: 1-5.

Cucherousset, J., S. Bouletreau, A. Martino, J. M. Roussel \& F. Santoul, 2012. Using stable isotope analyses to determine the ecological effects of non-native fishes. Fisheries Management and Ecology 19: 111-119.

Eby, L. A., W. J. Roach, L. B. Crowder \& J. A. Stanford, 2006. Effects of stocking-up freshwater food webs. Trends in Ecology \& Evolution 21: 576-584.

Froese, R., 2006. Cube law, condition factor and weight-length relationships: history, meta-analysis and recommendations. Journal of Applied Ichthyology 22: 241-253.

Fry, B. \& C. Arnold, 1982. Rapid ${ }^{13} \mathrm{C} /{ }^{12} \mathrm{C}$ turnover during growth of brown shrimp (Penaeus aztecus). Oecologia 54: 200-204.

Heady, W. N. \& J. W. Moore, 2013. Tissue turnover and stable isotope clocks to quantify resource shifts in anadromous rainbow trout. Oecologia 172: 21-34.

Hertz, E., M. Trudel, R. El-Sabaawi, S. Tucker, J. F. Dower, T. D. Beacham, A. M. Edwards \& A. Mazumder, 2016. Hitting the moving target: modelling ontogenetic shifts with stable isotopes reveals the importance of isotopic turnover. Journal of Animal Ecology 85: 681-691.

Herzka, S. Z. \& G. J. Holt, 2000. Changes in isotopic composition of red drum (Sciaenops ocellatus) larvae in response to dietary shifts: potential applications to settlement studies. Canadian Journal of Fisheries and Aquatic Sciences 57: 137-147.

Hesslein, R. H., K. A. Hallard \& P. Ramlal, 1993. Replacement of sulfur, carbon and nitrogen in tissue of growing broad whitefish (Coregonus nasus) in response to a change in diet 
traced by $\delta^{34} \mathrm{~S}, \delta^{13} \mathrm{C}$ and $\delta^{15} \mathrm{~N}$. Canadian Journal of Fisheries and Aquatic Sciences 50: 2071-2076.

Ho, S. S., N. R. Bond \& R. M. Thompson, 2013. Does seasonal flooding give a native species an edge over a global invader? Freshwater Biology 58: 159-170.

Hobson, K. A. \& R. G. Clark, 1992. Assessing avian diets using stable isotopes I: turnover of ${ }^{13} \mathrm{C}$ in tissues. Condor 94 : 181-188.

Kishi, D., M. Murakami, S. Nakano \& K. Maekawa, 2005. Water temperature determines strength of top-down control in a stream food web. Freshwater Biology 50: 1315-1322.

Logan, J., H. Haas, L. Deegan \& E. Gaines, 2006. Turnover rates of nitrogen stable isotopes in the salt marsh mummichog, Fundulus heteroclitus, following a laboratory diet switch. Oecologia 147: 391-395.

Maruyama, A., H. Shimonaka \& T. Ito, 2015. Quick change in delta N-15 values of fish mucus confirmed in the field using a migratory goby. Ecology of Freshwater Fish 24: 162-164.

Maruyama, A., E. Tanahashi, T. Hirayama \& R. Yonekura, 2017. A comparison of changes in stable isotope ratios in the epidermal mucus and muscle tissue of slow-growing adult catfish. Ecology of Freshwater Fish 26: 636-642.

Mazerolle, M.J. 2017. AICcmodavg: model selection and multimodel inference based on (Q)AIC(c). R package version 2.1-1.

Perga, M. E. \& D. Gerdeaux, 2005. 'Are fish what they eat' all year round? Oecologia 144: 598-606.

Phillips, D. L. \& P. M. Eldridge, 2006. Estimating the timing of diet shifts using stable isotopes. Oecologia 147: 195-203.

R Core Team. 2017. R: a language and environment for statistical computing. R Foundation for Statistical Computing, Vienna.

Roth, J. D. \& K. A. Hobson, 2000. Stable carbon and nitrogen isotopic fractionation between diet and tissue of captive red fox: implications for dietary reconstruction. Canadian Journal of Zoology 78: 848-852.

Shigeta, K., S. Tsuma, R. Yonekura, H. Kakamu \& A. Maruyama, 2017. Isotopic analysis of epidermal mucus in freshwater fishes can reveal short-time diet variations. Ecological Research 32: 643-652.

Suzuki, K. W., A. Kasai, K. Nakayama \& M. Tanaka, 2005. Differential isotopic enrichment and half-life among tissues in Japanese temperate bass (Lateolabrax japonicus) juveniles: implications for analyzing migration. Canadian Journal of Fisheries and Aquatic Sciences 62: 671-678.

Tarboush, R. A., S. E. MacAvoy, S. A. Macko \& V. Connaughton, 2006. Contribution of catabolic tissue replacement to the turnover of stable isotopes in Danio rerio. Canadian Journal of Zoology-Revue Canadienne De Zoologie 84: 1453-1460.

Thomas, S. M. \& T. W. Crowther, 2015. Predicting rates of isotopic turnover across the animal kingdom: a synthesis of existing data. Journal of Animal Ecology 84: 861-870.

Tieszen, L. L., T. W. Boutton, K. G. Tesdahl \& N. A. Slade, 1983. Fractionation and turnover of stable carbon isotopes in aminal tissues: implications for $\delta^{13} \mathrm{C}$ analysis of diet. Oecologia 57: 32-37.

Vander Zanden, M. J., M. K. Clayton, E. K. Moody, C. T. Solomon \& B. C. Weidel, 2015. Stable isotope turnover and half-life in animal tissues: a literature synthesis. Plos One 10: 1-16.

Vašek, M., L. Vejř́k, I. Vejř́́ková, M. Šmejkal, R. Baran, M. Muška, J. Kubečka \& J. Peterka, 2017. Development of non-lethal monitoring of stable isotopes in asp (Leuciscus aspius): a comparison of muscle, fin and scale tissues. Hydrobiologia 785: 327-335.

Vilizzi, L., A. S. Tarkan \& G. H. Copp, 2015. Experimental evidence from causal criteria analysis for the effects of Common Carp Cyprinus carpio on freshwater ecosystems: a global perspective. Reviews in Fisheries Science \& Aquaculture 23: 253-290.

Weidel, B. C., S. R. Carpenter, J. F. Kitchell \& M. J. Vander Zanden, 2011. Rates and components of carbon turnover in fish muscle: insights from bioenergetics models and a whole-lake C-13 addition. Canadian Journal of Fisheries and Aquatic Sciences 68: 387-399.

Witting, D. A., R. C. Chambers, K. L. Bosley \& S. C. Wainright, 2004. Experimental evaluation of ontogenetic diet transitions in summer flounder (Paralichthys dentatus), using stable isotopes as diet tracers. Canadian Journal of Fisheries and Aquatic Sciences 61: 2069-2084.

Zambrano, L., E. Valiente \& M. J. Vander Zanden, 2010. Food web overlap among native axolotl (Ambystoma mexicanum) and two exotic fishes: carp (Cyprinus carpio) and tilapia (Oreochromis niloticus) in Xochimilco, Mexico City. Biological Invasions 12: 3061-3069. 